\title{
Penentuan Prioritas Pemeliharaan Jalan Kabupaten
}

\section{Trissiyana}

Fakultas Teknik Program Studi Teknik Sipil Universitas Antakusuma Pangkalan Bun

\begin{abstract}
ABSTRAK. Sesuai dengan karakteristiknya, jalan mempunyai kecenderungan mengalami penurunan kondisi yang diindikasikan dengan terjadinya kerusakan pada perkerasan jalan. Untuk memperlambat laju penurunan kondisi dan mempertahankan kondisi pada tingkat yang layak, jalan tersebut perlu dikelola pemeliharaannya dengan baik agar dapat berfungsi sepanjang waktu, sehingga memerlukan perencanaan yang baik dalam penentuan prioritas pemeliharaan jalan kabupaten di Kabupaten Kotawaringin Barat. Tujuan dari penelitian ini adalah mengetahui urutan faktor-faktor yang mempengaruhi prioritas pemeliharaan ruasruas jalan kabupaten di Kabupaten Kotawaringin Barat, urutan prioritas pemeliharaan jalan per jenis pemeliharaan, urutan faktor-faktor kendala penentuan prioritas pemeliharaan jalan dan urutan alternative solusi peningkatan pemeliharaan jalan. Berdasarkan hasil analisis, dalam penentuan prioritas pemeliharaan jalan diperoleh urutan faktor-faktor yang mempengaruhi penentuan pemeliharaan jalan kabupaten, yaitu Faktor Ekonomi dengan mean 4,64, Faktor Kebijakan dengan mean 4,27, Faktor Klasifikasi Jalan Menurut Fungsi dengan mean 4,11, Faktor Tata Guna Lahan dengan mean 4,03, Faktor Kondisi Jalan dengan mean 3,56 Faktor Volume Lalu Lintas, dengan mean 3,24. Urutan prioritas pemeliharaan jalan per jenis pemeliharaan adalah Pemeliharaan Rutin Jalan, dengan mean 4,68, Rehabilitasi Jalan dengan mean 4,34, Pemeliharaan Berkala Jalan dengan mean 4,18. Berdasarkan urutan faktor-faktor yang menjadi kendala dalam penentuan prioritas pemeliharaan jalan kabupaten adalah kurangnya petugas pengamat jalan untuk melakukan penilaian kerusakan jalan, tidak seimbangnya antara dana dengan jalan yang dipelihara dan kurangnya koordinasi antar penentu kebijakan dengan stakeholder. Urutan alternatif solusi peningkatan pemeliharaan jalan kabupaten yaitu identifikasi kerusakan yang lebih detail, pemeliharaan yang tepat sasaran, pelaksanaan yang tepat sesuai rencana, memberikan pelatihan teknis yang sesuai, menambah tenaga yang berpengalaman.
\end{abstract}

Kata Kunci : Jalan, kabupaten, prioritas, pemeliharaan

\section{PENDAHULUAN}

Kebutuhan untuk bergerak dari satu tempat ke tempat yang lain pada hakikatnya merupakan salah satu kebutuhan dalam kehidupan rnanusia perpindahan manusia tersebut didasari oleh kenyataan bahwa sumber kebutuhan manusia tidak terdapat di satu tempat saja (Warpani, 1990). Sistem transportasi sebagai suatu sistem yang terdiri dari sarana dan prasarana serta sistem pelayanan yang memungkinkan adanya pergerakan ke seluruh wilayah sehingga mobilitas penduduk terakomodasi dan pergerakan barang yang lancar.

Sesuai dengan karakteristiknya, jalan mempunyai kecenderungan mengalami 
penurunan kondisi yang diindikasikan dengan terjadinya kerusakan pada perkerasan jalan. Untuk memperlambat laju penurunan kondisi dan mempertahankan kondisi pada tingkat yang layak, jalan tersebut perlu dikelola pemeliharaannya dengan baik agar dapat berfungsi sepanjang waktu. Kabupaten Kotawaringin Barat mempunyai wilayah sangat luas yang terdiri dari 6 kecamatan dan desa-desa dengan potensi dan kondisi yang berbeda, hal ini merupakan permasalahan tersendiri bagi Pemerintah Kabupaten Kotawaringin Barat dalam menentukan pembangunan daerah, termasuk dalamnya pemeliharaan jalan. Dengan Jumlah ruas jalan kabupaten sebanyak 253 ruas jalan, dan dengan panjang ruas jalan $1.182,505 \mathrm{~km}$, sehingga karena panjangnya ruas jalan yang membutuhkan pemeliharaan, ditambah lagi keterbatasan dana yang mengakibatkan tidak memungkinkannya pemeliharaan jaringan jalan dapat dilakukan sekaligus dalam 1 (satu) tahun anggaran untuk semua ruas jalan, sehingga memerlukan perencanaan yang baik dalam penentuan prioritas pemeliharaan jalan kabupaten di Kabupaten Kotawaringin Barat.

Oleh karena itu, penelitian ini bertujuan untuk menentukan prioritas pemeliharaan jalan kabupaten di Kabupaten Kotawaringin Barat berdasarkan keterpaduan antara kriteria dan mekanisme kondisi eksisting di Dinas Pekerjaan Umum, DPRD dan Bappeda Kabupaten Kotawaringin Barat.

Dalam perkembangan pembangunan selanjutnya di Kabupaten Kotawaringin Barat perlu dilakukan pemerataan pembangunan di segala bidang, sehingga sangat diperlukan faktor-faktor pendukung seperti tersedianya jalan yang stabil dan selalu mendapat penanganan, karena bila kondisi jalan tidak ditangani secara tepat tidak akan mencapai umur rencana.

Kegiatan penanganan jalan berupa pemeliharaan jalan yaitu pemeliharaan rutin, pemeliharaan berkala, dan rehabilitasi. Karena Keterbatasan dana yang tersedia mengakibatkan perlunya penentuan prioritas pemeliharaan jalan kabupaten di Kabupaten Kotawaringin Barat.

\section{METODE PENELITIAN}

Penelitian ini termasuk jenis penelitian survei. Alur penelitian ini dimulai dengan melakukan studi pendahuluan yang meliputi : pengenalan daerah studi, tinjauan pustaka, identifikasi data dan perangkat lunak yang digunakan. Dari studi pendahuluan yang dilakukan, dilanjutkan identifikasi masalah sehingga dapat disusun latar belakang masalah dan rumusan masalah serta penetapan tujuan penelitian ini. Selanjutnya dilakukan pengumpulan data baik diperoleh dari data primer maupun dari data sekunder. Data primer dalam penelitian ini diperoleh melalui kuisioner atau wawancara kepada pihak-pihak (stakeholders) yang berkompeten dalam pemeliharaan jalan kabupaten di Kabupaten Kotawaringin Barat. Sedangkan data sekunder dalam penelitian ini diperoleh dari data jalan kabupaten di Kabupaten Kotawaringin Barat. Langkah selanjutnya akan dilakukan penentuan prioritas pemeliharaan jalan kabupaten di Kabupaten Kotawaringin Barat.

\section{Lokasi, Waktu dan Obyek Penelitian}

Hasil dari studi pendahuluan ini adalah sebagai berikut lokasi penelitian di Kabupaten Kotawaringin Barat, waktu penelitian, penelitian ini dilakukan dari pagi hingga sore selama jam kerja pemerintahan, obyek penelitian dilakukan pada Asisten Pembangunan Setda Kabupaten Kotawaringin Barat, Bidang Bina Marga Dinas PU Kab.Kobar, Badan Pembangunan Daerah (Bappeda) Kab.Kobar, Anggota DPRD pada Komisi Pembangunan, Camat di Kecamatan Kab. Kobar, dengan kriteria mempunyai tingkat pendidikan minimal Sarjana Strata 1 (S1), serta pernah terlibat langsung dalam menentukan prioritas pemeliharaan jalan kabupaten, dengan alasan untuk dapat memperoleh jawaban pertanyaan yang berkualitas dan memberikan penilaian terhadap subyek yang akan dinilai.

\section{Metode Analisis Data}

Untuk menganalisis data penelitian ini, digunakan bantuan Software SPSS 16 dengan memakai Metode Statistik Deskriptif. Software SPSS juga digunakan untuk analisis uji 
viliditas dan reliabilitas kuisioner yang digunakan.

Untuk mengukur pengaruh masingmasing variabel, digunakan skala likert $1-5$ dengan kriteria tertentu. Berikut tabel kriteria pengukuran variabel pada penelitian ini.

Tabel 1. Kriteria Pengukuran Variabel

\begin{tabular}{cccc}
\hline \multicolumn{2}{c}{ Skor jawaban } & \multicolumn{2}{c}{ Kriteria } \\
\hline Skala & Keterangan & Mean & Keterangan \\
\hline 1 & Sangat Tidak Setuju & $1,00-1,50$ & Sangat Rendah \\
2 & Tidak Setuju & $1,51-2,50$ & Rendah \\
3 & Ragu-ragu & $2,51-3,50$ & Sedang \\
\hline
\end{tabular}

Adapun dasar pengambilan keputusan dari uji validitas menggunakan program SPSS adalah sebagai berikut (Santoso, 2000):
1. Jika $r$ hasil positif, serta $r$ hasil $>r$ tabel, maka butir/variabel tersebut Valid.

2. Jika $r$ hasil tidak positif, dan/atau $r$ hasil $<\mathrm{r}$ tabel, maka butir/variabel tersebut tidak valid.

Sedangkan untuk menguji reliabilitas suatu angket dasar pengambilan keputusannya adalah: apabila $\alpha$ positif, serta $\alpha>$ r tabel, maka butir atau variabel tersebut reliabel. Sedangkan jika $\alpha$ negatif dan/atau $\alpha<$ r tabel, maka butir atau variabel tersebut tidak reliabel.

\section{HASIL DAN PEMBAHASAN}

Deskripsi kriteria dan urutan masingmasing variable secara ringkas ditampilkan dalam tabel berikut ini :

Tabel 2. Kriteria Skor dan Urutan Variabel Penelitian

\begin{tabular}{|c|c|c|c|c|}
\hline & Faktor & Mean & Kriteria & Urutan \\
\hline & aktor-faktor yang mempengaruhi penent & itas per & haraan jalan kab & ten: \\
\hline A & Faktor Kondisi Jalan & 3,56 & Tinggi & $\mathrm{V}$ \\
\hline 1 & Perbaikan lubang-lubang & 4,21 & Tinggi & 1 \\
\hline 2 & Perbaikan legokan/amblas & 3,82 & Tinggi & 2 \\
\hline 3 & Perbaikan retak-retak & 3,18 & Sedang & 5 \\
\hline 4 & Perbaikan alur bekas roda & 3,5 & Sedang & 4 \\
\hline 5 & Perbaikan bahu jalan & 3,05 & Sedang & 6 \\
\hline 6 & Perbaikan kemiringan jalan & 3,58 & Tinggi & 3 \\
\hline $\mathrm{B}$ & Faktor Volume Lalu Lintas & 3,24 & Sedang & VI \\
\hline 1 & Truk ringan & 3,39 & Sedang & 3 \\
\hline 2 & Truk sedang dan berat & 2,74 & Sedang & 5 \\
\hline 3 & Bis & 2,87 & Sedang & 4 \\
\hline 4 & Mobil roda empat & 3,39 & Sedang & 2 \\
\hline 5 & Sepeda motor & 3,79 & Tinggi & 1 \\
\hline $\mathrm{C}$ & Faktor Ekonomi & 4,64 & Sangat Tinggi & $\mathrm{I}$ \\
\hline 1 & Manfaat /kelayakan & 4,68 & Sangat Tinggi & 1 \\
\hline 2 & Biaya kegiatan & 4,61 & Sangat Tinggi & 2 \\
\hline $\mathrm{D}$ & Faktor Kebijakan & 4,27 & Tinggi & II \\
\hline 1 & Musrenbang Camat & 4,55 & Sangat Tinggi & 1 \\
\hline 2 & Musrenbang Kabupaten & 4,39 & Tinggi & 2 \\
\hline 3 & Musrenbang Provinsi & 4,21 & Tinggi & 3 \\
\hline 4 & Anggaran Biaya Tambahan & 3,92 & Tinggi & 4 \\
\hline $\mathrm{E}$ & Faktor Tata Guna Lahan & 4,03 & Tinggi & IV \\
\hline 1 & Penunjang bidang pertanian & 2,26 & Rendah & 4 \\
\hline 2 & Penunjang bidang pendidikan & 4,74 & Sangat Tinggi & 1 \\
\hline 3 & Penunjang bidang sosial budaya & 4,53 & Sangat Tinggi & 3 \\
\hline 4 & Penunjang bidang perdagangan dan jasa & 4,58 & Sangat Tinggi & 2 \\
\hline $\mathrm{F}$ & Faktor klasifikasi jalan menurut fungsi & 4,11 & Tinggi & III \\
\hline 1 & Jalan Arteri & 4,26 & Tinggi & 2 \\
\hline 2 & Jalan Kolektor & 4,66 & Sangat Tinggi & 1 \\
\hline 3 & Jalan Lokal & 3.42 & Sedang & 3 \\
\hline & eliharaan jalan yang dilakukan & 4,4 & Tinggi & \\
\hline 1 & Pemeliharaan Rutin Jalan & 4,68 & Sangat Tinggi & 1 \\
\hline 2 & Pemeliharaan Berkala Jalan & 4,18 & Tinggi & 3 \\
\hline 3 & Rehabilitasi Jalan & 4,34 & Tinggi & 2 \\
\hline
\end{tabular}

Sumber : Data Primer yang diolah, 2016 
Dari Tabel 1 diatas faktor-faktor yang mempengaruhi penentuan pemeliharaan jalan kabupaten, dapat dijelaskan sebagai berikut :

1. Faktor Kondisi Jalan

Faktor kondisi jalan dengan nilai mean 3,56 (Kriteria Tinggi), merupakan faktor yang mempengaruhi penentuan pemeliharaan jalan kabupaten di Kabupaten Kotawaringin Barat, dan faktor kondisi jalan pada perbaikan lubang-lubang mempunyai nilai mean yang paling tinggi 4,21 (kriteria tinggi) yang berarti sangat mempengaruhi dalam penentuan pemeliharaan jalan kabupaten.

\section{Faktor Volume Lalu Lintas}

Faktor volume lalu lintas dengan nilai mean 3,24 (kriteria sedang), merupakan faktor yang mempengaruhi dalam menentukan pemeliharaan jalan kabupaten di Kabupaten Kotawaringin Barat, dan faktor volume lalu lintas urutan ke 1 yang mempengaruhi dalam penentuan pemeliharaan jalan kabupaten mempunyai nilai mean 4,71 (Kriteria sangat tinggi ) yaitu volume truk sedang dan berat.

\section{Faktor Ekonomi}

Faktor ekonomi dengan nilai mean 4,64 (Kriteria sangat tinggi), merupakan faktor yang sangat mempengaruhi dalam menentukan pemeliharaan jalan kabupaten di Kabupaten Kotawaringin Barat, dan faktor ekonomi pada manfaat dan kelayakan yang mempunyai nilai mean yang tinggi 4,68 (Kriteria sangat tinggi) yang berarti sangat mempengaruhi dalam penentuan pemeliharaan jalan kabupaten.

\section{Faktor Kebijakan}

Faktor kebijakan dengan nilai mean 4,27 (Kriteria tinggi ), merupakan faktor yang sangat mempengaruhi dalam menentukan pemeliharaan jalan kabupaten di Kabupaten Kotawaringin Barat, dan faktor kebijakan pada Musrembang Kecamatan di urutan ke 1 yang mempunyai nilai mean yang paling tinggi 4,55 (Kriteria sangat tinggi) yang berarti sangat mempengaruhi dalam penentuan pemeliharaan jalan kabupaten.

\section{Faktor Tata Guna Lahan}

Faktor tata guna lahan dengan nilai mean 4,03 (Kriteria tinggi), merupakan faktor yang mempengaruhi dalam menentukan pemeliharaan jalan kabupaten di Kabupaten Kotawaringin Barat, dan faktor tata guna lahan urutan ke 1 yang sangat mempengaruhi dalam penentuan pemeliharaan jalan kabupaten mempunyai nilai mean 4,74 (Kriteria sangat tinggi) yaitu penunjang bidang pendidikan.

\section{Faktor Klasifikasi Jalan Menurut Fungsi \\ Faktor klasifikasi jalan menurut fungsi} dengan nilai mean 4,11 (Kriteria tinggi), merupakan faktor yang sangat mempengaruhi dalam menentukan pemeliharaan jalan kabupaten di Kabupaten Kotawaringin Barat, dan faktor klasifikasi jalan menurut fungsi urutan ke 1 yang sangat mempengaruhi dalam penentuan pemeliharaan jalan kabupaten mempunyai nilai mean 4,66 (Kriteria sangat tinggi) yaitu jalan dengan fungsi sebagai jalan kolektor.

Dari Tabel diatas, juga dapat diketahui bahwa pemeliharaan jalan yang dilakukan mempunyai nilai mean 4,4 (Kriteria tinggi) yang menyatakan bahwa pemeliharaan jalan kabupaten di Kabupaten Kotawaringin Barat telah dilakukan dengan sangat baik, dengan pemeliharaan rutin jalan di urutan 1 dengan nilai mean 4,68 (Kriteria sangat tinggi).

Pada Gambar 1. diketahui bahwa faktor ekonomi merupakan faktor yang sangat mempengaruhi penentuan prioritas pemeliharaan jalan kabupaten di Kabupaten Kotawaringin Barat, hal ini dapat terlihat di jalan-jalan kabupaten yang mempunyai nilai ekonomi atau nilai manfaat/kelayakan selalu cepat mendapat perhatian untuk diperbaiki apabila ada kerusakan. 
Faktor-Faktor yang Mempengaruhi Penentuan Prioritas

Pemeliharaan Jalan Kabupaten

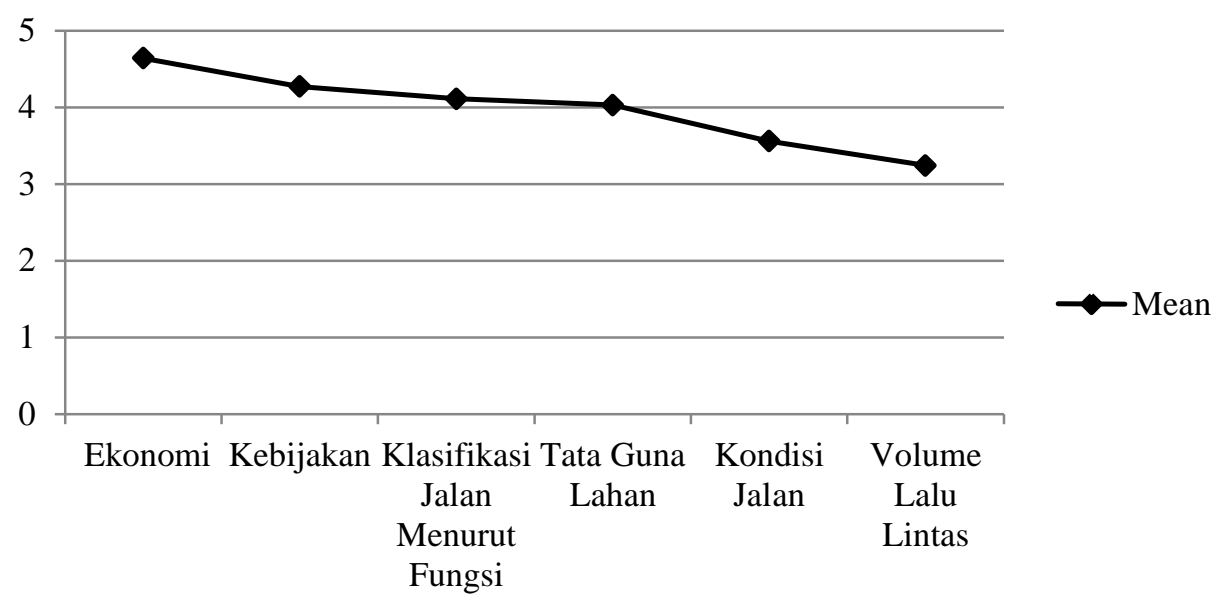

Gambar 1. Urutan Faktor yangMempengaruhi Penentuan Prioritas Pemeliharaan Jalan Kabupaten

Tabel 3. Hasil analisis perhitungan dengan nilai skor Faktor-Faktor Yang Menjadi Kendala Dalam Penentuan Prioritas Pemeliharaan Jalan Kabupaten

\begin{tabular}{lcccc}
\hline \multicolumn{1}{c}{$\begin{array}{c}\text { Urutan Faktor-faktor } \\
\text { yang menjadi kendala }\end{array}$} & \multicolumn{2}{c}{ Urutan x Skor } & \\
\cline { 2 - 3 } $\begin{array}{c}\text { dalam penentuan } \\
\text { prioritas pemeliharaan } \\
\text { jalan kabupaten }\end{array}$ & I & II & III & \\
\hline $\begin{array}{l}\text { Kurangnya petugas } \\
\text { pengamat jalan untuk }\end{array}$ & 84 & 14 & 3 & 101 \\
$\begin{array}{l}\text { melakukan penilaian } \\
\text { kerusakan jalan }\end{array}$ & & & & \\
$\begin{array}{l}\text { Kurangnya koordinasi } \\
\text { antar penentu kebijakan }\end{array}$ & 9 & 4 & 33 & 46 \\
$\begin{array}{l}\text { dengan stakeholder } \\
\text { Tidak seimbangnya } \\
\text { antara dana dengan jalan }\end{array}$ & 21 & 58 & 2 & 81 \\
yang dipelihara & & & & \\
\hline
\end{tabular}

Diketahui bahwa urutan faktor yang menjadi kendala dalam penentuan prioritas pemeliharaan jalan kabupaten sebagai berikut: 1. Kurangnya petugas pengamat jalan untuk melakukan penilaian kerusakan jalan dengan nilai skor 101

2. Tidak seimbangnya antara dana dengan jalan yang dipelihara dengan nilai skor 81

3. Kurangnya koordinasi antar penentu kebijakan dengan stakeholder di Urutan III dengan nilai skor 46.
Tabel 4. Hasil analisis perhitungan dengan nilai skor Alternatif Solusi Peningkatan Pemeliharaan Jalan Kabupaten

\begin{tabular}{|c|c|c|c|c|c|c|}
\hline \multirow{2}{*}{$\begin{array}{c}\text { Urutan alternatif solusi } \\
\text { peningkatan } \\
\text { pemeliharaan jalan } \\
\text { kabupaten }\end{array}$} & \multicolumn{5}{|c|}{ Urutan x Skor } & \multirow{2}{*}{ Jumlah } \\
\hline & I & II & III & IV & $\mathrm{V}$ & \\
\hline $\begin{array}{l}\text { Identifikasi } \\
\text { yang detail }\end{array}$ & $\begin{array}{l}14 \\
0\end{array}$ & 36 & 3 & 0 & 0 & 179 \\
\hline $\begin{array}{l}\text { Pemeliharaan yang tepat } \\
\text { sasaran }\end{array}$ & 50 & 28 & 63 & 0 & 0 & 141 \\
\hline $\begin{array}{l}\text { Pelaksanaan yang tepat } \\
\text { sesuai rencana }\end{array}$ & 0 & 60 & 48 & 14 & 0 & 122 \\
\hline $\begin{array}{l}\text { Menambah tenaga yang } \\
\text { berpengalaman }\end{array}$ & 0 & 0 & 0 & 30 & 23 & 53 \\
\hline $\begin{array}{l}\text { Memberikan pelatihan } \\
\text { teknis yang sesuai }\end{array}$ & 0 & 28 & 0 & 32 & 15 & 75 \\
\hline
\end{tabular}

Dari hasil perhitungan skor diatas, yang menyatakan urutan alternatif solusi peningkatan pemeliharaan jalan kabupaten pada masing masing pertanyaan yaitu:

1. Identifikasi kerusakan yang lebih detail dengan jumlah skor 179

2. Pemeliharaan yang tepat sasaran dengan jumlah skor 141

3. Pelaksanaan yang tepat sesuai rencana dengan jumlah skor 122

4. Memberikan pelatihan teknis yang sesuai dengan jumlah skor 75

5. Menambah tenaga yang berpengalaman dengan jumlah skor 53 . 


\section{KESIMPULAN}

Berdasarkan hasil penelitian dan pembahasan dapat disimpulkan sebagai berikut:

1. Urutan faktor-faktor yang mempengaruhi penentuan pemeliharaan jalan kabupaten adalah :

a. Faktor Ekonomi, dengan mean 4,64

b. Faktor Kebijakan, dengan mean 4,27

c. Faktor Klasifikasi Jalan Menurut Fungsi, dengan mean 4,11

d. Faktor Tata Guna Lahan, dengan mean 4,03

e. Faktor Kondisi Jalan, dengan mean 3,56

f. Faktor Volume Lalu Lintas, dengan mean 3,24

2. Urutan prioritas pemeliharaan jalan per jenis pemeliharaan adalah :

a. Pemeliharaan Rutin Jalan, dengan mean 4,68

b. Rehabilitasi Jalan, dengan mean 4,34

c. Pemeliharaan Berkala Jalan, dengan mean 4,18

3. Berdasarkan urutan faktor-faktor yang menjadi kendala dalam penentuan prioritas pemeliharaan jalan kabupaten adalah :

a. Kurangnya petugas pengamat jalan untuk melakukan penilaian kerusakan jalan.

b. Tidak seimbangnya antara dana dengan jalan yang dipelihara

c. Kurangnya koordinasi antar penentu kebijakan dengan stakeholder

4. Urutan alternatif solusi peningkatan pemeliharaan jalan kabupaten pada masing masing pertanyaan yaitu:

a. Identifikasi kerusakan yang lebih detail

b. Pemeliharaan yang tepat sasaran

c. Pelaksanaan yang tepat sesuai rencana

d. Memberikan pelatihan teknis yang sesuai

e. Menambah tenaga yang berpengalaman

\section{SARAN}

Berdasarkan hasil penelitian, analisis penelitian serta kesimpulan dapat disarankan sebagai berikut:
1. Bagi pemerintah agar senantiasa mengawasi dan meningkatkan pengawasan terhadap pelaksanaan pemeliharaan jalan agar pemeliharaan jalan kabupaten dapat berjalan dengan baik.

2. Untuk peningkatan pemeliharaan jalan kabupaten selain mengadakan identifikasi kerusakan yang lebih detail, juga harus diperhatikan pelaksanaan yang tepat sesuai rencana, pemeliharaan yang tepat sasaran, memberikan pelatihan teknis yang sesuai, dan menambah tenaga yang berpengalaman.

\section{DAFTAR PUSTAKA}

Brodjonegoro, P.S., 1991, Petunjuk Mengenai Teori dan Aplikasi dari Model The Analytic Hierarchy Process, Sapta Utama, Jakarta.

Dessler, G., 1992, Manajemen Personalia, Erlangga, Jakarta

Desutama, Odang,H.S, Mahmud, Salim dan hadiana, 2003, Sistem Manajemen Jalan, Departemen Permukiman dan Prasarana Wilayah, Jakarta.

DPU Dirjen Bina Marga, 1992, Standar Perencanaan Geometrik untuk jalan Perkotaan, Departemen Pekerjaan Umum, Jakarta.

Dirjen Bina Marga, 1990, Petunjuk Teknis Perencanaan dan Penyusunan Program Jalan Kabupaten, Surat Keputusan No.77/KPTS/Db/1990, Dinas Pekerjaan Umum RI, Jakarta.

Dirjen Perhubungan Darat, 2005, Peraturan Pemerintah No.26 tahun 1985, tentang jalan, Departemen Perhubungan Republik Indonesia, Jakarta.

Dirjen Perhubungan Darat, 2009, UndangUndang Republik Indonesia No.22, Th.2009 Tentang Lalu lintas Jalan, Departemen Perhubungan RI, Jakarta.

Firdaus, M.A., 2008, Skala Pengukuran dan Instrumen Penelitian, http://azisartikel.Blogspoot.com.

Gibson, J. L., Ivancevich, J. M., dan Donnnelly, Jr., J. H., 1996, Organisasi Perilaku,Struktur Proses, Penerbit Erlangga, Jakarta.

Hasan, M. I., 2003, Pokok-pokok Materi 
Statistik. Edisi Kedua, PT Bumi Aksara, Jakarta.

Karya, I W., 2004, Skala Prioritas Penanganan Jaringan Jalan Pada Ruas-ruas Jalan Di Kabupaten Gianyar, Tesis, Universitas Udayana, Denpasar.

Mulyono, A., 2006, Teori Pengambilan Keputusan, PT Bumi Aksara, Jakarta.

Peraturan Pemerintah No.14 Th.1988, tentang Penyerahan Urusan Pemerintahan di Bidang Pekerjaan Umum kepada Daerah, Jakarta: Bappenas.

Peraturan Menteri Dalam Negeri No.59 Th.2007, tentang Pedoman Pengelolaan Keuangan Daerah. Sekretariat Republik Indonesia.

Putri, I Dewa Ayu Ngurah Alit, Penentuan Skala Prioritas Penangan Jalan di Kabupaten Bangli.

Saaty, T. L., 1986, Proses Hirarki Analitik untuk Pengambilan Keputusan Dalam Situasi yang Kompleks, PT Pustaka Binman Pressindo, Jakarta.

Saleh, M., 2006, Kerusakan jalan Nasional Ditinjau dari Aspek Pelaksanaan, Tesis, Program Pascasarjana Teknik Sipil Universitas Islam Sultan Agung, Semarang.

Santoso, S., 2000, Buku Latihan SPSS Statistik Parametrik, PT. Elex Media kompotindo, Jakarta.

Sjrafruddin, A., 1997, Studi Kelayakan Proyek Transportasi, FTSP-ITB, Bandung.

Sugiyono, 2009, Metode Penelitian Kuantitatif, Alfabeta, Bandung.
Suhendi. Chrisna,. Ratnawati Alifah., Mulyana., Kendar., Sobari, Agus., Wikaningrum. T, Laboratorium Statistik dengan SPSS, Materi Kuliah Magister Teknik Sipil, Pascasrjana Universitas Islam Sultan Agung, Pusat Pengembagan Manajemen Fakultas Ekonomi Unissula, Semarang.

Suyasa, D. G., 2007, Penentuan Skala Prioritas Penanganan Jalan Kabupaten Badung dengan Metode AHP, Tesis, Program Magister Teknik Sipil Universitas Udayana, Denpasar.

Undang -Undang No.32. Th. 2004, tentang Penyelenggaraan Sistem Pemerintahan Daerah, Jakarta: Bappenas.

Usman, H., 1996, Metodelogi Penelitian Sosial, Bumi Aksara, Jakarta.

Wahyudi Imam. S, 2013, Matematika Terapan (Statistik), Materi Kuliah, Magister Teknik Sipil Unissula, Semarang.

Warpani, S., 1990, Merencanakan Sitem Perangkutan, Penerbit ITB, Bandung

Warpole, Ronald. E, dan Raumod H. Myers, 1996, Ilmu Peluang dan Statistika untuk Insinyur dan Ilmuawan, Penerbit ITB, Bandung.

Wibowo, K., 2013, Manajemen Konstruksi, Materi Kuliah Magister Teknik Sipil Unissula, Semarang.

Widhiastuti, Y., Analisis Faktor-Faktor Yang Mempengaruhi Kerusakan Jalan Propinsi, Tesis, Program Magister Teknik Sipil, Program Pascasarjana Universitas Islam Sultan Agung, Semarang. 